\title{
Proposal of Roseburia faecis sp. nov., Roseburia hominis sp. nov. and Roseburia inulinivorans sp. nov., based on isolates from human faeces
}

Correspondence
Harry J. Flint
hjf@rri.sari.ac.uk

Strict anaerobes that produced butyrate as a major product were isolated from human faecal samples. Most butyrate producers from human faeces were found previously to belong to two main groups, clostridial cluster IV (Duncan et al., 2002b) and cluster XIVa (Hold et al., 2003; Barcenilla et al., 2000). Particularly prevalent among the latter group were bacteria related to Roseburia cecicola. Roseburia intestinalis was proposed previously based on isolates from human faeces (Duncan et al., 2002a) and the purpose of the present paper is to propose three novel species of the genus Roseburia.

Butyrate-producing strains were isolated from the highest countable dilution of faecal samples from a healthy infant and from four healthy adults. Ethical approval was obtained from Grampian Research Ethics Committee (project number 00/00133). The isolations were made from roll

The GenBank/EMBL/DDBJ accession numbers for the 16S rRNA gene sequences of Roseburia strains determined in this study are given in Fig. 1. tubes of anaerobic M2GSC medium (Miyazaki et al., 1997) or a medium designed to select for Selenomonas-like bacteria, as described previously (Louis et al., 2004). All media were prepared and maintained anaerobically using oxygen-free carbon dioxide. The isolates were maintained routinely by growth for $16-18 \mathrm{~h}$ at $37^{\circ} \mathrm{C}$ in $7 \cdot 5 \mathrm{ml}$ aliquots of M2GSC medium.

DNA was extracted and purified from $24 \mathrm{~h}$-old cultures grown on M2GSC medium following the method of Ausubel et al. (1994). A universal primer set was used for amplification of the 16S rRNA gene (Weisburg et al., 1991). PCR conditions were as described by Wood et al. (1998). On-line similarity analysis of the 16S rRNA gene sequences was performed with the BLAST program at NCBI and EMBL and with the Ribosomal Database Project (Maidak et al., 2001). Nucleotide sequences were aligned with reference $16 \mathrm{~S}$ rRNA gene sequences using the CLUSTAL_X program (Thompson et al., 1997). Phylogenetic analyses were performed using neighbour-joining (Saitou \& Nei, 1987) and maximum-likelihood (Felsenstein \& Churchill, 1996) 


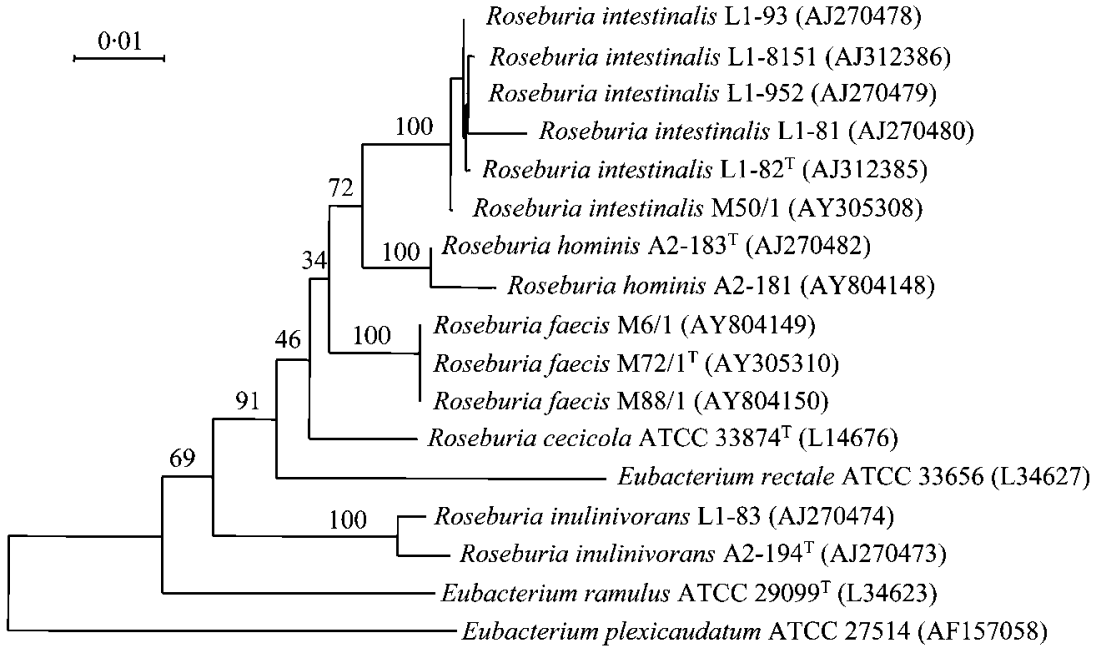

Fig. 1. Phylogenetic tree constructed by using the maximum-likelihood method, based on 16S rRNA gene sequences of Roseburia-related strains. 1150 unambiguous nucleotide positions were used in the phylogenetic reconstruction; positions with gaps were omitted from the analysis. Numbers above nodes are confidence levels generated from 100 bootstrap trees. The 16S rRNA gene sequence of Eubacterium plexicaudatum was used as an outgroup. Bar, 0.01 substitutions per nucleotide position. GenBank accession numbers are given in parentheses. methods in the PHYLIP package (Felsenstein, 1989) and parsimony analysis with the PAUP package (Swofford, 2002). Statistical validation of tree branching was done by bootstrap analysis (Felsenstein, 1989), involving 1000 resampled trees in the neighbour-joining and parsimony methods and 100 trees in the maximum-likelihood analysis.

Fig. 1 shows a phylogenetic tree based on 16S rRNA gene sequences for 13 isolates, obtained from three individuals. Six sequences of isolates from two individuals clustered with $R$. intestinalis. The remaining seven sequences, however, did not correspond to recognized species and fell into three clusters within the tree (Fig. 1). None of the isolates was close enough to $R$. cecicola, originally isolated from the mouse gut (Stanton \& Savage, 1983), for inclusion in this species. Based on their phylogenetic placement and phenotypic characteristics (reported below), we propose that each of the three clusters represents a novel species, with $\mathrm{A} 2-183^{\mathrm{T}}, \mathrm{M} 72 / 1^{\mathrm{T}}$ and $\mathrm{A} 2-194^{\mathrm{T}}$ as the representative type strains. A matrix of $16 \mathrm{~S}$ rRNA gene sequence comparisons showed that strains $\mathrm{A} 2-183^{\mathrm{T}}, \mathrm{M} 72 / 1^{\mathrm{T}}$ and $\mathrm{A} 2-194^{\mathrm{T}}$ shared $97 \cdot 3,95 \cdot 4$ and $92 \cdot 7 \%$ sequence similarity, respectively, with R. intestinalis $\mathrm{L} 1-82^{\mathrm{T}}$. Strains $\mathrm{A} 2-183^{\mathrm{T}}$ and $\mathrm{M} 72 / 1^{\mathrm{T}}$ shared $95.4 \%$ similarity with each other and $93 \%$ similarity with strain $\mathrm{A} 2-194^{\mathrm{T}}$. Strains clustering with $\mathrm{A} 2-183^{\mathrm{T}}$ and $\mathrm{M} 72 / 1^{\mathrm{T}}$ shared $>97 \%$ similarity with the relevant type strain; however, strain L1-83 shared $95 \cdot 5 \%$ similarity with strain A2- $194^{\mathrm{T}}$.

The DNA G $+\mathrm{C}$ content was determined using highperformance liquid chromatography (at DSMZ, Germany) (Tamaoka \& Komagata, 1984; Mesbah et al., 1989); values for representative strains $\mathrm{A} 2-183^{\mathrm{T}}, \mathrm{A} 2-194^{\mathrm{T}}$ and $\mathrm{M} 72 / 1^{\mathrm{T}}$ were $47 \cdot 4,41 \cdot 4$ and $42 \cdot 0 \mathrm{~mol} \%$, respectively. The G+C content of $R$. intestinalis $\mathrm{L} 1-82^{\mathrm{T}}$, determined here for comparison using the same method, was $42 \cdot 6 \mathrm{~mol} \%$.

The cellular morphology of all the isolates was observed under an Olympus BX50 light microscope at $\times 1000$ magnification, following Gram-staining of exponential and stationary phase cultures grown at $37^{\circ} \mathrm{C}$ on M2GSC medium, as described by Holdeman et al. (1977).

Following incubation of the cultures on complex growth medium in roll tubes at $37^{\circ} \mathrm{C}$ for $48 \mathrm{~h}$, single colonies of three representative strains $\left(\mathrm{A} 2-183^{\mathrm{T}}, \mathrm{M} 72 / 1^{\mathrm{T}}\right.$ and $\mathrm{A} 2-194^{\mathrm{T}}$ ) were small (1-3 $\mathrm{mm}$ in diameter), creamy white and translucent with entire edges. All 13 strains studied here were Gram-variable, slightly curved rods and all were motile. $R$. intestinalis $\mathrm{L} 1-82^{\mathrm{T}}$ had been shown previously to be motile by the presence of multiple flagella located subterminally (Duncan et al., 2002a) and strain A2-183 ${ }^{\mathrm{T}}$ also possessed a multiple flagellar bundle (Fig. 2). All representative strains failed to grow at 4 or $20^{\circ} \mathrm{C}$, all showed weak growth at $30^{\circ} \mathrm{C}$ and optimum growth at $37^{\circ} \mathrm{C}$.

Eight strains were tested for tolerance to oxygen by spreading late exponential cultures on the surface of pre-reduced agar plates and exposing the plates to air for different periods of time. R. intestinalis L1-82 ${ }^{\mathrm{T}}$, L1-952 and L1-8151 and strains

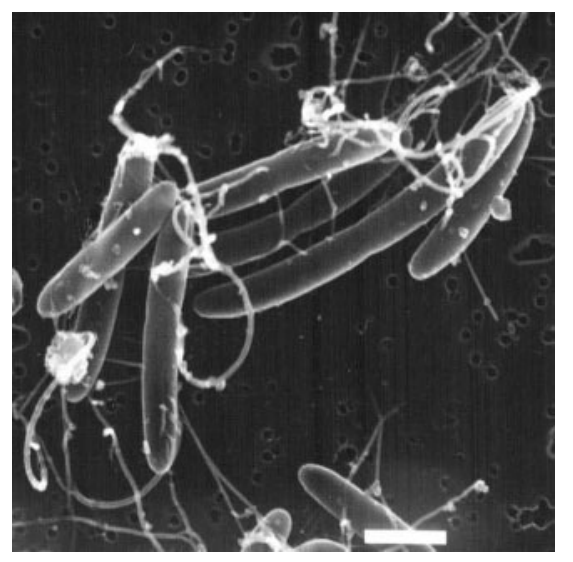

Fig. 2. Scanning electron micrograph of Roseburia hominis sp. nov. strain $A 2-183^{\top}$, showing a flagellar bundle. Bar, $1 \mu \mathrm{m}$. 
A2-181, A2-183 ${ }^{\mathrm{T}}, \mathrm{M} 6 / 1, \mathrm{M} 72 / 1^{\mathrm{T}}$ and $\mathrm{A} 2-194^{\mathrm{T}}$ all failed to grow after a minimum exposure time of 2 min to air, whereas the control plates that remained in the glove box (in an atmosphere of $80 \%$ nitrogen, $10 \%$ carbon dioxide and $10 \%$ hydrogen) gave good growth with viable counts of approximately $10^{8}$ c.f.u. $\mathrm{ml}^{-1}$ (data not shown).

Substrate utilization was determined by addition of a final concentration of $0.5 \%$ of stock $(10 \%$, w/v) filter-sterilized sugar solutions to YCFA medium (Duncan et al., 2002b), dispensed in $7.5 \mathrm{ml}$ amounts in Hungate tubes. YCFA medium supplemented with a carbon source provided a convenient alternative to rumen fluid medium for the cultivation of the strains in this study. Growth was measured spectrophotometrically as absorbance at $650 \mathrm{~nm}$.

Eleven strains representing $R$. intestinalis (five strains) and the three additional Roseburia-related clusters were tested for their ability to grow on a range of carbohydrate substrates in liquid medium (Table 1 ). Only $R$. intestinalis and strains $\mathrm{A} 2-181$ and $\mathrm{A} 2-183^{\mathrm{T}}$ were able to grow with arabinose as the sole added energy source. In common with $R$. cecicola, strains clustering with $R$. intestinalis and a second cluster comprising strains L1-83 and A2-194 ${ }^{\mathrm{T}}$ were able to grow (weakly) with sucrose as energy source. The other strains tested, belonging to two other distinct clusters, failed to grow on sucrose. In common with $R$. cecicola, but in contrast to the other three Roseburia species, strains A2-181 and $\mathrm{A} 2-183^{\mathrm{T}}$ were able to grow with glycerol. Only the two strains $\mathrm{M} 6 / 1$ and $\mathrm{M} 72 / 1^{\mathrm{T}}$, in common with $R$. cecicola, grew on sorbitol.
Previous observations revealed variation in the ability of Roseburia-related strains to utilize polysaccharides that occur in the human diet (Duncan et al., 2003). As summarized in Table 1 , only strains $\mathrm{M} 6 / 1, \mathrm{M} 72 / 1^{\mathrm{T}}$, A2$194^{\mathrm{T}}$ and L1-83 were able to grow with inulin (dahlia) as substrate. $R$. intestinalis strains in particular grew well with oat spelt xylan as substrate, whereas strains M6/1 and M72/ $1^{\mathrm{T}}$ grew weakly on this substrate. Starch utilization was widespread, with only two strains (A2-181 and A2-183 ${ }^{\mathrm{T}}$ ) failing to grow well with amylopectin (from potato starch; Fluka) as substrate.

All the Roseburia-related strains formed butyrate as a major fermentation product when grown on M2GSC medium at $37^{\circ} \mathrm{C}$ for $24 \mathrm{~h}$ and utilized acetate (Table 2). All strains formed between 14 and $24 \mathrm{mM}$ butyrate with the exception of two strains (L1-83 and A2-194 ${ }^{\mathrm{T}}$ ) that formed less than $7 \cdot 3 \mathrm{mM}$ butyrate and also utilized the lowest concentrations of acetate. All strains formed formate and lactate.

Two strains belonging to one cluster (A2-181 and A2-183 ${ }^{\mathrm{T}}$ ) had the highest $\mathrm{G}+\mathrm{C}$ content $(47 \cdot 4 \mathrm{~mol} \%)$ and shared $97 \%$ sequence similarity with $R$. intestinalis $\mathrm{L} 1-82^{\mathrm{T}}$; these were the only strains that failed to grow on all the complex carbohydrate substrates tested (inulin, xylan and amylopectin). Strains belonging to a second cluster (M6/1 and $\left.\mathrm{M} 72 / \mathrm{1}^{\mathrm{T}}\right)$ differed from strains A2-181 and $\mathrm{A} 2-183^{\mathrm{T}}$ in their ability to grow on sorbitol and amylopectin. Isolates belonging to a third cluster (L1-83 and A2-194 ${ }^{\mathrm{T}}$ ) shared approximately $93 \%$ sequence similarity with $R$. intestinalis L1 $-82^{\mathrm{T}}$ and in addition were the only strains to give good

Table 1. Substrate utilization by strains belonging to the genus Roseburia

Growth was tested in liquid cultures with $0.5 \%(\mathrm{w} / \mathrm{v})$ substrate, by comparison with controls that received no added carbohydrate. All strains are positive for fermentation of cellobiose, fructose, maltose and glucose. $\Delta \mathrm{OD}_{650}$ values at $24 \mathrm{~h}:+,>0 \cdot 4, \mathrm{~W},>0 \cdot 15$ and $<0 \cdot 4$. For R. cecicola, + indicates a significant reduction in culture $\mathrm{pH}$. -, Negative; NR, not recorded.

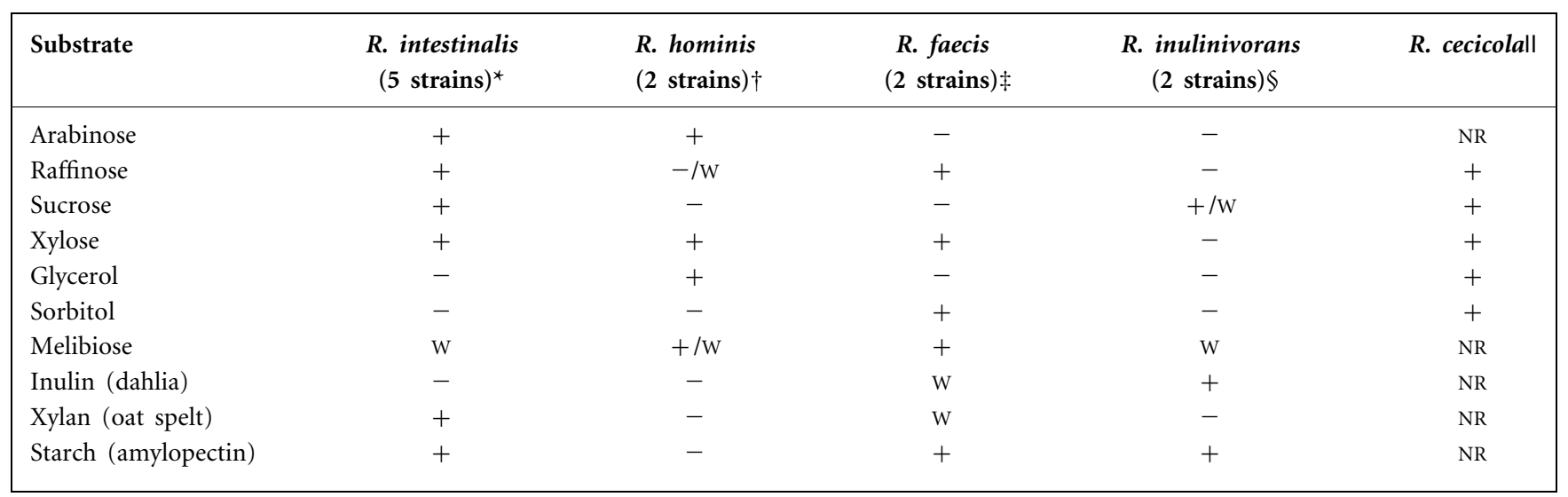

${ }^{*} \mathrm{~L} 1-81, \mathrm{~L} 1-93, \mathrm{~L} 1-952, \mathrm{~L} 1-8151$ and L1-82 ${ }^{\mathrm{T}}$.

$\dagger \mathrm{A} 2-181$ and $\mathrm{A} 2-183^{\mathrm{T}}$.

$\ddagger \mathrm{M} 6 / 1$ and $\mathrm{M} 72 / 1^{\mathrm{T}}$.

\$L1-83 and A2-194 ${ }^{\mathrm{T}}$.

IIData from Stanton \& Savage (1983) based on measurement of final culture pH rather than optical density; this strain is no longer extant and direct comparison with the newer isolates was not possible. 
Table 2. Range of short chain fatty acids (mM) formed and utilized by Roseburia strains on M2GSC medium $n$, Number of strains studied.

\begin{tabular}{|lcccc|}
\hline Compound & $\boldsymbol{R}$. intestinalis $(\boldsymbol{n}=\mathbf{4})^{*}$ & $\boldsymbol{R}$. faecis $(\boldsymbol{n}=\mathbf{3}) \dagger$ & $\boldsymbol{R}$. hominis $(\boldsymbol{n}=\mathbf{2})$ & $\boldsymbol{R}$. inulinivorans $(\boldsymbol{n}=\mathbf{2})$ \\
\hline Acetate utilized & $9 \cdot 1-12 \cdot 3$ & $3 \cdot 6-8 \cdot 3$ & $8 \cdot 2-11 \cdot 5$ & $2 \cdot 3-3 \cdot 5$ \\
Butyrate formed & $16 \cdot 0-21 \cdot 3$ & $13 \cdot 9-24 \cdot 0$ & $16 \cdot 8-20 \cdot 0$ & $6 \cdot 5-7 \cdot 3$ \\
Formate formed & $6 \cdot 9-8 \cdot 4$ & $9 \cdot 2-15 \cdot 7$ & $6 \cdot 9-7 \cdot 6$ & $4 \cdot 4-4 \cdot 7$ \\
Lactate formed & $0-7 \cdot 1$ & $0-2 \cdot 3$ & $2 \cdot 2-9 \cdot 1$ & $2 \cdot 1-7 \cdot 1$ \\
\hline
\end{tabular}

${ }^{\star}$ Strains as in Table 1 , but without L1-81.

$\dagger$ Strains as in Table 1, with the addition of M88/1.

growth on inulin (strains $\mathrm{M} 6 / 1$ and $\mathrm{M} 72 / 1^{\mathrm{T}}$ gave weak growth).

The latest description of the genus Roseburia includes the species $R$. intestinalis and R. cecicola, the latter being the type species. The genus description can be taken to apply to the three novel species proposed below.

\section{Emended description of Roseburia intestinalis Duncan et al. 2002}

The description is as given by Duncan et al. (2002a). The $\mathrm{G}+\mathrm{C}$ content of the DNA of the type strain $\left(\mathrm{L} 1-82^{\mathrm{T}}\right)$ is $42 \cdot 6 \mathrm{~mol} \%$.

\section{Description of Roseburia hominis sp. nov.}

Roseburia hominis (hom.i' nis. L. gen. n. hominis, of a human being, referring to human gut habitat).

Cells are Gram-variable to Gram-negative, slightly curved rods, and motile by means of multiple flagella. Cells measure approximately $0.5 \times 1.5-5 \mu \mathrm{m}$. Optimum growth temperature is $37^{\circ} \mathrm{C}$. Strictly anaerobic. Good growth occurs on M2GSC agar at $37^{\circ} \mathrm{C}$ and after incubation for $48 \mathrm{~h}$ forms creamy white translucent colonies with entire edges, approximately $1-3 \mathrm{~mm}$ in diameter. Chemo-organotrophic. Utilizes arabinose, fructose, glucose, maltose, cellobiose, xylose and glycerol as energy sources for growth. Weak/no growth occurs with raffinose or melibiose as energy source. Sucrose, sorbitol, oat spelt xylan, amylopectin starch and inulin (dahlia) are not utilized for growth. Butyrate and formate are major products and lactate a minor product from glucose $(0.2 \%)$, with net consumption of acetate present in the medium. Catalase-negative. The $\mathrm{G}+\mathrm{C}$ content of the DNA of the type strain is $47 \cdot 4 \mathrm{~mol} \%$.

Isolated from human faeces in Aberdeen, Scotland. The type strain is $\mathrm{A} 2-183^{\mathrm{T}}\left(=\mathrm{DSM} 16839^{\mathrm{T}}=\right.$ NCIMB $\left.14029^{\mathrm{T}}\right)$.

\section{Description of Roseburia inulinivorans sp. nov.}

Roseburia inulinivorans (in.ul'in.i'vor.ans. N.L. n. inulinum, inulin; L. part. adj. vorans, devouring; N.L. part. adj. inulinivorans inulin-devouring, referring to the ability to use inulin as a growth substrate).

Cells are Gram-variable to Gram-negative, motile, slightly curved rods. Cells measure approximately $0.5 \times 1 \cdot 5-5 \mu \mathrm{m}$. Optimum growth temperature is $37^{\circ} \mathrm{C}$. Strictly anaerobic. Good growth occurs on M2GSC agar at $37^{\circ} \mathrm{C}$ and after incubation for $48 \mathrm{~h}$ forms creamy white translucent colonies with entire edges, approximately $1-3 \mathrm{~mm}$ in diameter. Chemo-organotrophic. Utilizes fructose, glucose, maltose, cellobiose, inulin (dahlia) and amylopectin starch as energy sources for growth. Weak growth occurs with sucrose or melibiose as energy source. Arabinose, raffinose, xylose, glycerol, sorbitol and oat spelt xylan are not utilized for growth. Butyrate, formate and some lactate are produced from glucose, with net consumption of acetate present in the medium. Catalase-negative. The $\mathrm{G}+\mathrm{C}$ content of the DNA of the type strain is $41 \cdot 4 \mathrm{~mol} \%$.

Isolated from human faeces in Aberdeen, Scotland. The type strain is $\mathrm{A} 2-194^{\mathrm{T}}\left(=\mathrm{DSM} 16841^{\mathrm{T}}=\right.$ NCIMB $\left.14030^{\mathrm{T}}\right)$.

\section{Description of Roseburia faecis sp. nov.}

Roseburia faecis (fae'cis. L. gen. n. faecis referring to faecal origin).

Gram-variable, motile, slightly curved rods. Cells measure approximately $0.5 \times 1 \cdot 5-5 \mu \mathrm{m}$. Optimum growth temperature is $37^{\circ} \mathrm{C}$. Strictly anaerobic. Good growth occurs on M2GSC agar at $37^{\circ} \mathrm{C}$ and after incubation for $48 \mathrm{~h}$ forms creamy white translucent colonies with entire edges, approximately $1-3 \mathrm{~mm}$ in diameter. Chemo-organotrophic. Utilizes fructose, glucose, maltose, cellobiose, raffinose, xylose, sorbitol, melibiose and amylopectin starch as energy sources for growth. Weak growth occurs with inulin or oat spelt xylan as energy source. Arabinose, sucrose and glycerol are not utilized for growth. Butyrate and formate are major products and lactate a minor product from glucose $(0.2 \%)$, with net consumption of acetate present in the medium. Catalase-negative. The G+C content of the DNA of the type strain is $42 \cdot 0 \mathrm{~mol} \%$. 
Isolated from human faeces in Aberdeen, Scotland. The type strain is $\mathrm{M} 72 / 1^{\mathrm{T}}\left(=\right.$ DSM $\left.16840^{\mathrm{T}}=\operatorname{NCIMB} 14031^{\mathrm{T}}\right)$.

\section{Acknowledgements}

We thank M. Jackson, J. C. Martin, K. Young, C. Nourissat, A. Barcenilla and A. Ramsay for technical help. The Rowett Research Institute is funded by the Scottish Executive Environment and Rural Affairs Department (SEERAD). We are grateful to Dr J. Euzeby for advice on species names and Latin usage.

\section{References}

Ausubel, F. M., Brent, R., Kingston, R. E., Moore, D. M., Seidman, J. G., Smith, J. A. \& Struhl, K. (1994). Current Protocols in Molecular Biology, vol. 1, section 2.4. New York: Wiley.

Barcenilla, A., Pryde, S. E., Martin, J. C., Duncan, S. H., Stewart, C. S., Henderson, C. \& Flint, H. J. (2000). Phylogenetic relationships of butyrate-producing bacteria from the human gut. Appl Environ Microbiol 66, 1654-1661.

Duncan, S. H., Hold, G. L., Barcenilla, A., Stewart, C. S. \& Flint, H. J. (2002a). Roseburia intestinalis sp. nov., a novel saccharolytic, butyrate-producing bacterium from human faeces. Int J Syst Evol Microbiol 52, 1615-1620.

Duncan, S. H., Hold, G. L., Harmsen, H. J. M., Stewart, C. S. \& Flint, H. J. (2002b). Growth requirements and fermentation products of Fusobacterium prausnitzii, and a proposal to reclassify it as Faecalibacterium prausnitzii gen. nov., comb. nov. Int J Syst Evol Microbiol 52, 2141-2146.

Duncan, S. H., Scott, K. P., Ramsay, A. G., Harmsen, H. J. M., Welling, G. W., Stewart, C. S. \& Flint, H. J. (2003). Effects of alternative dietary substrates on competition between human colonic bacteria in an anaerobic fermentor system. Appl Environ Microbiol 69, 1136-1142.

Felsenstein, J. (1989). PHYLIP - Phylogeny inference package (version 3.2). Cladistics 5, 164-166.

Felsenstein, J. \& Churchill, G. A. (1996). A hidden Markov model approach to variation among sites in rate of evolution. Mol Biol Evol 13, 93-104.

Hold, G. L., Schwiertz, A., Aminov, R. I., Blaut, M. \& Flint, H. J. (2003). Oligonucleotide probes that detect quantitatively significant groups of butyrate-producing bacteria in human feces. Appl Environ Microbiol 69, 4320-4324.

Holdeman, L. V., Cato, E. P. \& Moore, W. E. C. (1977). Anaerobe Laboratory Manual, 4th edn. Blacksburg: Virginia Polytechnic Institute and State University.

Louis, P., Duncan, S. H., McCrae, S. I., Millar, J., Jackson, M. S. \& Flint, H. J. (2004). Restricted distribution of the butyrate kinase pathway among butyrate-producing bacteria from the human colon. J Bacteriol 186, 2099-2106.

Maidak, B. L., Cole, J. R., Lilburn, T. G. \& 7 other authors (2001). The RDP-II (Ribosomal Database Project). Nucleic Acids Res 29, 173-174.

Mesbah, M., Premachandran, U. \& Whitman, W. B. (1989). Precise measurement of the $\mathrm{G}+\mathrm{C}$ content of deoxyribonucleic acid by highperformance liquid chromatography. Int J Syst Bacteriol 39, 159-167.

Miyazaki, K., Martin, J. C., Marinsek-Logar, R. \& Flint, H. J. (1997). Degradation and utilization of xylans by the rumen anaerobe Prevotella bryantii (formerly $P$. ruminicola subsp. brevis) $\mathrm{B}_{1} 4$. Anaerobe 3, 373-381.

Saitou, N. \& Nei, M. (1987). The neighbor-joining method: a new method for reconstructing phylogenetic trees. Mol Biol Evol 4, 406-425.

Stanton, T. B. \& Savage, D. C. (1983). Colonization of gnotobiotic mice by Roseburia cecicola, a motile, obligately anaerobic bacterium from murine ceca. Appl Environ Microbiol 45, 1677-1684.

Swofford, D. L. (2002). PAUP ${ }^{\star}$ - Phylogenetic Analysis Using Parsimony (*and other methods), version 4. Sunderland: Sinauer Associates.

Tamaoka, J. \& Komagata, K. (1984). Determination of DNA base composition by reversed-phase high-performance liquid chromatography. FEMS Microbiol Lett 25, 125-128.

Thompson, J. D., Gibson, T. J., Plewniak, F., Jeanmougin, F. \& Higgins, D. G. (1997). The CLUSTAL_X windows interface: flexible strategies for multiple sequence alignment aided by quality analysis tools. Nucleic Acids Res 25, 4876-4882.

Weisburg, W. G., Barns, S. M., Pelletier, D. A. \& Lane, D. J. (1991). 16S ribosomal DNA for phylogenetic study. J Bacteriol 173, 697-703.

Wood, J., Scott, K. P., Avgustin, G., Newbold, C. J. \& Flint, H. J. (1998). Estimation of the relative abundance of different Bacteroides and Prevotella ribotypes in gut samples by restriction enzyme profiling of PCR-amplified 16S rRNA gene sequences. Appl Environ Microbiol 64, 3683-3689. 